\title{
Xbrl technologies for financial reporting in information systems
}

\author{
Alaa A. Qaffas ${ }^{1}$, Ahmed Zamzam ${ }^{1}$ \\ ${ }^{1}$ College of Business, University of Jeddah, KSA \\ aaqaffas@uj.edu.sa \\ afzamzam@uj.edu.sa
}

\begin{abstract}
Without a common format, the financial community has been constantly penalized by the data exchange process. Currently, when financial data are dematerialized, they are exchanged in a multitude of formats: Excel files, free text, PDF, etc. Often not much more suitable for processing than photocopying and limited to certain platforms, these formats prove unsuitable for the exchange of information between programs, for analysis, comparison and presentation of reports to users. So far, despite a strong tendency to use XML syntax, attempts at convergence have struggled to generalize and apply to many sectors and contexts.

In recent years, reporting requirements have led to a significant increase in the cost of using financial systems. The use of XBRL technology, using XML syntax, supported by many players in the world of finance, the software industry and adapted to reporting, can constitute the solution. Many governments, regulators, financial institutions are already using XBRL or have pilot projects in place.
\end{abstract}

This document specifically targets XBRL. This technology, which is now recognized by the entire software industry, provides tremendous benefits for data exchange, storage, research and processing.

Indexing terms/Keywords:XBRL, XML, taxonomies, information systems, financial reporting, IFRS.

SubjectClassification:Information, communication (94Axx)

Type (Method/Approach):Literature Review

Language : English

Date of Submission : 2018-08-17

Date of Acceptance : 2018-09-20

Date of Publication : 2018-09-26

DOI 10.24297/ijmit.v13i0.7609

ISSN : 2278-5612

Volume : 13 Issue : 1

Journal : INTENATIONAL JOURNAL OF MANAGEMENT AND INFORMATION TECHNOLOGY

Publisher : CIRWORLD

Website : https://cirworld.com

This work is licensed under a Creative Commons Attribution 4.0 International License. 


\section{Introduction}

XBRL (eXtensible Business Reporting Language) is a declarative language based on the XML (eXtensibleMarkup Language) standard, designed to be a universal language for expression, dematerialization and electronic transmission of financial data. Its mastery and expansion are therefore a major challenge for regulators and banks that today struggle to exchange their data in Text, Excel, PDF, HMTL formats... XBRL is an open format, led by regulators, government agencies and software vendors united in the form of a consortium: XBRL International Incorporated. This consortium is divided into independent, often national, jurisdictions with a dual purpose. On the one hand, these jurisdictions are responsible for developing the necessary classifications locally for the evolution of the language and on the other hand, they oversee lobbying financial actors to push the adoption of the standard.

The idea is XBRL not only to facilitate the exchange of financial data but also to speed up and facilitate analysis. This problem, inherent to the Data Web that we have been talking about for several years (more often under the Semantic Web name), is always the same: that of the egg or the hen. Because to carry out interesting analyses, you need a large quantity of data, but to have such data, they must have been produced. However, regulatory bodies and banks do not necessarily see the point of producing these data, since for the moment, no mass analysis is possible.

But for XBRL, this barrier to entry will soon be completely circumvented: important structures, such as the Securities and Exchange Commission (SEC) in the United States [1], have already included it in their exchange logic and do not hesitate to share their knowledge of the standard on portals, leading to the membership of some accounting firms (e.g. Price Waterhouse Coopers) who have trained their managers in the use of the language. The SEC has gone even further by requiring some companies to publish their financial results using XBRL, initially focusing on high-value companies. Japan, the Netherlands, Australia and England also use XBRL.

XBRL spearheads a new political will (public access to data is often the flagship measure of a transparent governance policy) and is often presented as a remedy for market opacity deemed responsible for all past crises, including the most recent. But XBRL will not reassure markets if they do not have reliable and efficient analysis tools. From a standard, XBRL will quickly become a massively adopted standard whose knowledge will be mandatory in IT-financial circles to master the information well (and obtain a return on the investment necessary to produce data in XBRL).

The other advantage of XBRL is that it introduces an extremely structuring abstraction layer: it is very easy to translate data labels. The translation of keywords ensures that a document can be available, as soon as it is published, in any other language. Of course, there are still difficulties to overcome such as the replacement of culturally used wordings by some companies by standardized wordings and the translation, still not automated, of text notes added to documents... By defining a common standard for all players, XBRL frees users from their dependence on proprietary formats that can only be edited by publishers' solutions and increases the speed of financial information processing by eliminating several human data entries and reading intermediaries between two companies. Thus, the investment is only focused on information processing.

In their pursuit to acclimatize to international adoption, information providers, consumers, software developers and the broader XBRL groups, will draw upon the utility of academic research [2]. Conceptual models and experiments [3], field-based studies [4] and empirically oriented analyses of XBRL data [5] all constitute the various research methods employed in this field of study, which has been carried out in an international context [6] because of the global reach of XBRL. While as Alles[2] has pointed out, research has focused on the nature and speed of XBRL implementation, research on the changing nature of XBRL and its role in XBRL research is still scant. However, as an integral feature of XBRL, its ongoing evolution offers broad scope for research opportunities and invites discussion. The following section will discuss these research prospects and surrounding topics.

\section{XBRL's Impact on Financial Reporting}

The area of financial reporting still takes precedence in the academic research about XBRL despite the fact that its implementation has crossed into varied arenas. This is perhaps because of the commercial origins of XBRL within the US financial services industry which sought out the most effective, cost efficient, way to analyze financial documents and improve transparency for investors. The scope of XBRL has a much further reach than this domain, but this area still provides significant advantages. 
Because of its ability to be programmatically integrated upon its reception, and the fact that pre-outlined business rules can be applied to the XBRL instance file, the speed and efficacy of XBRL is what makes it favored by marketing and regulatory analysts. It is a cost-effective way to reduce the 'time to analysis', electronically communicate reports using the Internet and make information easier to combine and compare using web-based investor relations portals, for example, which can even add value, generate revenue or help to retain or acquire custom. This, in turn, means that XBRL can even facilitate a greater frequency of financial reporting and improve the quality and availability of information. It is anticipated that the so-far steady momentum of the adoption of XBRL will increase, fueling a new period in financial reporting and in the consolidation, benchmarking and analytical web services through its ability to quickly query and compare data for business analysts.

It is taxonomy- a system of classifying, identifying and structuring information so consumers can find information easily- that is a crucial part of XBRL. A good example of taxonomy in use would be in retail, to facilitate the retrieval, review and selection of products in online sales: taxonomy in this context would be inclusive of codes and labels (categories such as size colour and price range) to identify products and uses short descriptions, delivery times and references to real-life retail spaces to quickly offer information about the products to the consumer. The capacity of taxonomies in structuring information electronically means it is easily accessible and processed effectively in terms of cost by the intended receiver of that information, such as a shopper placing an online order through the selection of a given item and the automatic processing of this selection by the retailed, using the computer code [7].

The International Financial Reporting Standards (IFRS) Taxonomy was first published in 2002 and was a collaborative product from XBRL International and IASB. Their taxonomy falls in line with IFRS and includes IAS (International Accounting standards) and incorporates the IFRS for Small and Medium Enterprises (SMEs). A guide was given alongside this which offers technical advice and support for IFRS taxonomy users. This combined approach using XBRL along with IFRS uses best practices and creates a regularized system with a view to improving transparency and quality for users and shareholders in the field of financial reporting. The IFRS foundation thus plays an integral part in the adoption of XBRL [8].

In a phased process over three years, beginning 15th June 2009, the SEC XBRL mandate necessitated XBRL implementation for Securities Act Registration statements in the USA [9]. Phase I firms, that is those businesses that fil US Generally Accepted Accounting Principles (GAAP) financial statements and with a world audience of over $\$ 5$ billion, were expected to adhere to XBRL reporting requirements for fiscal periods ending or beyond 15th June 2009. Following this, by June 15th, 2010, other large submitters of US GAAP financial statements made up Phase II and had to adhere to XBRL standards. Phase III firms were those that remained and had to meet requirements by June 15th, 2011. The tagging of information was staggered over this period, requirements in terms of detail increased over the period with the initial phases only necessitated tag blocking from the notes, with later phases requiring detailed tagging of all financial statements and notes.

Capital market research about the implementation of XBRL has centered on the assessment of the efficacy of capital markets by using cost of capital, earnings response coefficients, reduction of analyst forecast errors as a measure, as well as other standard trials used to test the quality of accounting and financial information transmission. The focus of Liu et al.'s [9] research was to examine the mandatory adoption of XBRL in the US by taking samples of Phase I and Phase II businesses in 2009 and 2010 to explore a potential correlation between the accuracy of analyst forecasts and the number of analysts following a particular firm. The outcome of their research in fact demonstrated there was a link between mandatory XBRL adoption, the number of followers and the accuracy of forecasts. More specifically, they noted demonstrable differences between Phase I and Phase II businesses: Phase I filers were shown to have more followers than Phase II in 2010, and, the followers were larger in number for Phase I filers in year two than in year one. There is clear evidence that points towards its adoption despite certain glitches and concerns arising in its initial implementation.

This interest in XBRL filings has reached far beyond the US and the SEC regulatory body [10], with the Canadian Securities Administrator instigating a voluntary XBRL program in 2007. Further still, China is necessitating an interactive filing program for more than 800 listed enterprises and Japan has a mandate for all companies to employ XBRL, which started with quarterly reports in the second quarter of 2008 . Australia began a pilot program and proof-of-concepts in 2008. This is with a goal to make financial statements more available and easily comparable by using technology. 
It is anticipated that XBRL will have a huge impact in the comparison of financial statements in a number of ways, according to [11]. The unique pinpointing of each line item on a financial statement, replete with appropriate tags, is the first way in which comparisons are facilitated, enabling users to draw out more data to look at alongside other statements by the users, as outlined by [12]. Secondly, as argued by [13], this information is readable by technology, assisting the effective and speedy searching of information and therefore improving transparency in reporting; managers are less able to manipulate the data on statements. In saying this, because companies can use their own categories, or extension taxonomies, which are allowed by the SEC in some instances, there is no evidence for the XBRL mandate's impact on the comparability of data.

\section{XBRL: Benefits and Challenges}

XBRL can be advantageous to all those who engage with financial information in all aspects of its 'supply chain' (regulators, private and public companies, accountants, auditors, analysts, investors, creditors, capital markets, software providers, and so on). Despite some trepidation about the XBRL introducing new accounting standards because of its association with the introduction of IFRS, this is not the case, and existing methods and approaches to accounting need not change as XBRL adapts to existing systems; it is still the main figures- chief financial officers who consistently control the publication of figures while XBRL simply facilitates the processing and transmission and communication and use (and re-use) of information [14; 15].

Despite moves towards more automatic data inputting, there are costly manual elements that still remain within report data, for example reinputting or re-entry by banks registries and administration, which can lead to errors and inconsistencies and also can lack systematization in terms of definitions and naming, further reducing accuracy. Where financial statements are not correctly created, communication with investors can suffer whereas XBRL, in contrast, is about sharing information more accurately and quickly, as well as its capacity to improve sharing networks and its analytical capabilities. Whether current practices involve paper or are already digitally oriented, the improved communication channels opened up by XBRL can improve innovations which have huge advantages and can pay off enormously [16].

At times, problems with communicating with the outside world can lead to a difficulty in the comprehension of financial reports and can lead to the impression that a company is hiding information, which means investors often turn to sometimes less reliable or less current sources of information. The potential for error in delay, penalties, costs, damages or a brand's image increases exponentially each time an auditor, regulator, analyst manually inputs information thus rendering the need and use of XBRL in avoiding such costs essential. Furthermore, it is the reduction of time and energy by avoiding the re-entering of data that further enhances its benefits, as well as the fact that existing information can be integrated more readily with broadly applicable standard formats. The fact that XML use in integration systems is augmenting is a reality. The communication with banks and rating agencies also has increased efficacy and minimizes time to wait and facilitates faster lending processes. XBRL reduces the need for research, capture and verification, increases competition, and frees up time for creativity and for the processing of modelling and forecasting in the processing of financial reports.

Service Oriented Architecture (SOA) provides a platform for multiple organizations to interact using different systems and languages and, like any number of XML technologies, XBRL integrates comfortably within SOA, functioning both within and outside of a business service. Reports can be verified in terms of their original data from its source with $X B R L$, and with its capacity to work alongside Web services and XML technologies, the exchange of more accurate and confidential data is enhanced. XBRL technology ensures clear guidelines and rules to be followed that furthermore leaving a traceable flow of information.

XBRL-based reporting is one part of new advancements in web and IT related areas that is leading to unstoppable changes in financial reporting. Neglecting this inevitable change and advancement would be like neglecting electronic spreadsheets in favor of their hard-copy versions in the late 1980s. The question is, what is need for its implementation? The goal is to provide useable information that functions across local, remote, external and internal applications by using a correctly architected XBRL platform that can hold XBRL documents, reports and taxonomies. The adaptability of formats - XBRL or other - and the conversion and routing of financial data from one system to another is a vital component of a successful XBRL intermediation system. All the advantages of XBRL are to do with its integration capacity and its methods of storage. Remaining unchanged, and housed in tabular structures, data in XBRL format must be distinguishable from the data in the information system. 
There are several other aspects that need considering, such as the fact that accounting software suppliers need to be mindful of XBRL. They should support it more evidently either within their products or by considering it in an export format. Further still, as is already in place in the US, auditors need to advance auditing standards that provide certificates on XBRL documents. It is also crucial that XBRL documents are transferable to other software supporting this format so that financial user applications can read this data.

Obstacles for business wanting to undertake XBRL are not technology-oriented but about decisions companies need to make about the exact taxonomies they use in their publications, and where exactly they should be placed. With this in mind, it will be important to work in a collaborative manner to develop geographically-, and sector-, specific taxonomies, as has been the situation in Europe with the IFRS and for the banking sector especially. Perhaps, more pragmatically, smaller businesses may rely upon the emergence of more standardized versions for their industries, perhaps through regulatory or accounting bodies within their location, while larger businesses may publish their own.

The main outcomes of $X B R L$ are as follows: a reduction in cost in preparing and using financial information and an increase in the exchange and quality by dividing its form and content. Following the successful development of a taxonomy, all participants in the financial process should be able to interpret and use XBRL documents, bringing more scope for flexibility for analysts and rating professionals. Greater automation will come about through the standardization of business rules and the use of the same data across different enterprises, reducing the need for costly re-entries, the inefficient task of developing ad-hoc solutions to problems and overall improving the homogenization of content and format which will improve comparison across companies and over time. With this, regulators will benefit from defining taxonomies from the outset and using standard Internet and XML technologies to receive and process data, minimizing costs of preparation, compilation, exchange and transmission of information.

\section{Case Studies}

Once an XBRL taxonomy is agreed and published, either for private or public use, it can then be used to implement a standard, programmatically-accessible reporting format, for use within an organization, across a business partner network, or within a national or transnational regulatory reporting framework for example. Potentially taxonomies can be created for:

Credit risk management: The banking industry has many opportunities to take advantage of XBRL. With XBRL, mechanical tasks can be performed much faster. This productivity gain can be used to reduce loan application acceptance time or to perform more thorough checks, leading to a competitive advantage. With the choice of a fast loan application, a small business can provide its bank, financial and administrative information in XBRL format and get a loan in days rather than weeks. The use of XBRL in credit risk calculation algorithms, financial analyses by rating companies certainly improve the effectiveness of credit risk analysis.

Business Intelligence: Decision support tools will take off considerably with the XBRL format. With up-to-date and reliable data available in the firm, managers and financiers have new sources of control and monitoring of activity and performance. Analysis, modeling, forecasting and reporting are greatly facilitated using XBRL.

Portfolio management and market data providers: For all these reasons, portfolio and market data are more accurate and more easily obtained and integrated. The banking sector is a major provider of financial data. Some banks that have developed their own ticker system may benefit from XBRL integration solutions.

Transaction cost analysis: Institutions that process a lot of data, such as banks, brokers, data providers, statistical agencies, are constantly analyzing their costs and trying to reduce them. Banks, for example, have hundreds of different mechanisms to consider when conducting their transactions. The initiative to reduce the complexity of these processes is called Straight-Through Processing (STP). All stakeholders have an interest in achieving STP, which can greatly benefit from the interests of XML and XBRL.

Solutions and prototypes: Partners between technology companies and financial sector players have already produced viable solutions using XBRL. The website http://www.xbrl.org provides a list of such projects. 


\section{Conclusions}

XBRL, like all dematerialization formats, makes it possible to avoid re-entering information, but it also makes it possible to precisely define the semantics of information, its context and, possibly, the reporting entity. XBRL uses XML syntax that allows to associate to each information, a standardized description that gives to each application the means to know the meaning of this data and its context (reporting entity, reference dates, units, precision, ...). The result is that each piece of information, after its introduction, can be understood and reused unambiguously by the entire reporting chain.

XBRL technology is ideal for web applications and all data exchanges over the Internet. Although this technology is in a preliminary adoption phase, the competitive advantage gained by using XBRL and XML is clear. The most technologically advanced governments, financial institutions, regulatory agencies and large corporations already use XBRL to obtain a certain return on investment both for their internal applications and for external exchanges.

It should be noted that in recent years new regulations have been developed, leading to more sophisticated reporting requirements to comply with IAS/IFRS-type constraints, etc. Companies of all sizes have had to take advantage of their information systems to meet these demands and, in return, have increased their capacity to analyze their activities. Organizations everywhere are beginning to understand how human resources, marketing, knowledge management, organizational structures, research and development affect their business. Many software solutions allow organizations to analyze all facets of their activities and their financial impacts.

With problems relating to the infancy of the language and the immaturity of the products relying on XBRL, obstacles for accounting departments and reporting agencies that want to invest in XBRL go way beyond a simple software upgrade or an add on to existing financial reporting packages. Over time, with strong and reliable technological developments to XBRL products from their prototype stages, providing a well-balanced overview of the advantages of XBRL will be much easier. Evidently, there are already clearly defined advantages in the changes to processes that XBRL enables but there are still elements of risk. One such risk is the time it would take for the financial industry to incorporate and become adept in its language compared to the potential evolving standards and disruptive technologies that may overtake the advantages of XBRL. A high level of comprehension of how XBRL can facilitate reporting is required, with an understanding of the benefits to a company's profit margins, in order for companies to weigh up the balance between quality, speed and quantity of reporting that is needed by the company in view of their cost constraints.

\section{Conflicts of Interest}

Theauthors of this work do not have any conflict of interests.

\section{References}

[1] Debreceny R.S., Chandra A., Cheh J.J., Guithues-Amrhein D., Hannon N.J., Hutchison P.D., et al. Financial Reporting in XBRL on the SEC's EDGAR System: A Critique and Evaluation. Journal of Information Systems 2005; 19(2):191-210.

[2] Alles M.G. The Evolution and Future of XBRL Research. International Journal of Accounting Information Systems 2012; 13(2):83-90.

[3] Pinsker R., Wheeler P. Nonprofessional investors' perceptions of the efficiency and effectiveness of XBRLenabled financial statement analysis and of firms providing XBRL-formatted information. International Journal of Disclosure and Governance 2009; 6(3):241-61.

[4] Janvrin, D., and W. G. No., forthcoming. XBRL Implementation: A Field Investigation to Identify Research Opportunities. Journal of Information Systems 2012; 26(1):169-197.

[5] Debreceny R.S., Farewell S, Piechocki M, Felden C, Gräning A, d'Eri A. Flex or Break? Causes and Consequences of Extensions in XBRL Disclosures to the SEC. Accounting Horizons 2011; 25(4):63157. 
[6] Bonsón E., Cortijo V., Escobar T. Towards the Global Adoption of XBRL Using International Financial Reporting Standards (IFRS). International Journal of Accounting Information Systems 2009; 10(1):4660.

[7] IASB (International Accounting Standards Board). Using the IFRS Taxonomy: A Preparer's Guide. December 2017.

[8] Singerova J. XBRL: Different Approach of Utilization. Procedia Economics and Finance 2015; 25: 134140.

[9] Liu Ch., Wang T., Yao J.L. XBRL's Impact on Analyst Forecast Behavior: An Empirical Study. Journal of Accounting and Public Policy 2014; 33: 69-82.

[10] Plumlee R.D., Plumlee M.A. Assurance on XBRL for Financial Reporting. Accounting Horizons 2008; 22(3): 353-368.

[11] Dhole S., Lobo G.J., Mishra S., Pal A.M. Effects of the SEC's XBRL Mandate on Financial Reporting Comparability. International Journal of Accounting Information Systems 2015; 19: 29-44.

[12] Vasarhelyi M.A., Chan D.Y., Krahel J.P. Consequences of XBRL Standardization on Financial Statement Data. Journal of Information Systems 2012; 26(1): 155-167.

[13] Hodge F.D., Kennedy J.J., Maines L.A. Does Search-Facilitating Technology Improve the Transparency of Financial Reporting? Accounting Review 2004; 79(3): 687-703.

[14] Blankespoor E, Miller BP, White HD. XBRL and Transition Period Market Frictions. Ann Arbor: University of Michigan; 2011.

[15] Kim JW, Lim J-H, No WG. The Effect of Mandatory XBRL Reporting across the Financial Information Environment: Evidence in the First Wave of Mandated U.S. Filers. Journal of Information Systems 2012; 26(1): 127-153.

[16] Bergeron B. Essentials of XBRL: Financial Reporting in the 21st Century. John Wiley \& Sons 2003; USA. 